\section{Over the limit?}

\section{The final phase of the European Working Time Directive came into force on 1 August. The BMJ reports from some of the affected countries}

Junior hospital doctors throughout Europe were supposed to start a new, shorter, 58 hour week from this month. Aimed at improving their working livesand their patients' safety-the European directive aims to reduce the limit further to just 48 hours by 2009. But despite the new rules, many doctors will continue to work long hours.

United Kingdom: A recent survey of 100 NHS chief executives by the NHS Confederation, which represents NHS management, showed that $16 \%$ did not expect their trusts to have complied with the European Working Time Directive by 1 August Junior doctors could take their employers to employment tribunals, and hospitals will be liable to fines of up to $£ 5000$ (\$9200; €7600) from the Health and Safety Executive each time they break the directive.

The BMA said that it will support UK doctors who take legal action against employers that do not limit their working hours to those set out in the directive.

The NHS has been struggling to meet the requirements of the new directive, but it is not alone in failing to do so fully.

Austria: Compliance with

the directive remains a distant prospect in Austria for doctors in training. Because of a shortage of staff most young doctors in hospitals regularly work more than the 60 hours a week maximum that is currently stipulated in Austrian law.

The Austrian Chamber of Doctors said that they will not take legal action because the law has so many loopholes. Instead, they will continue publicising the heavy workload of young doctors.

Czech Republic: As the directive also applies in the 10 new countries that joined the European Union on 1 May, the Czech Republic has to comply. This has not yet happened, however, and head of the Doctors Union, Milan Kubek, said that the union is preparing lega action against the health and labour ministries: "We are very unhappy that doctors are still working longer hours, and since we have been unable to reach agreement with ministers we have been forced to resort to the courts." So far doctors are not refusing to work the extra hours

Portugal: Non-compliance with the directive is the rule rather than the exception.

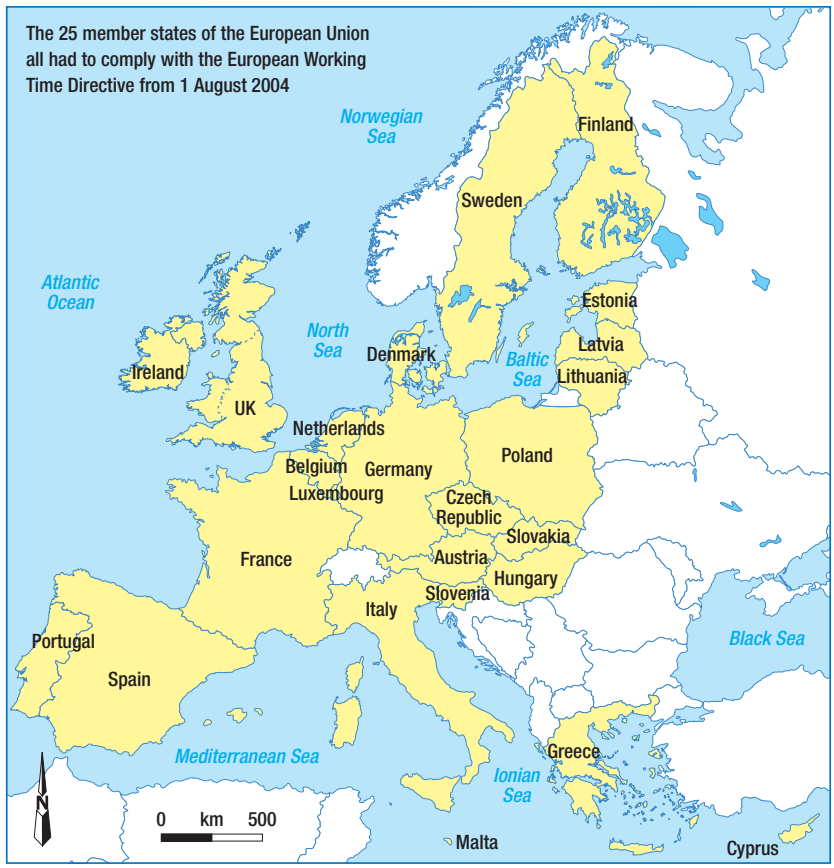

Almost all of the doctors working in the national health service exceed the 58 hour limit because they accumulate overtime shifts (in emergency departments) in addition to the 42 hours of their standard working week. These shifts are needed to make up for the shortage of doctors.

Spain: In general, resident doctors (in specialist training) have to work overtime doing a substantial number of on-call shifts in emergency departments, which results in a total number of working hours well above the limit.

Manuel Menéndez, presiden of the Spanish Association of Resident Doctors considers it unlikely that Spain will comply with the directive in the near future.

\section{The NHS is not alone in failing to fully meet the requirements of the new directive}

Germany: Although German law is harmonised with the directive, most hospital doctors working hours exceed those stipulated in the directive, said a spokesperson for the German Hospital Doctors Association.

Currently, the association and the civil servants' union are negotiating a new contract with hospitals that satisfies the directive and takes into consideration that on-call hours are also valued as full working hours. Strikes and new court cases are not on the agenda.

France: In France a doctor's week is counted in half days; but nowhere is it stipulated how many hours make up a half day.

Doctors in training, for example, work 11 half days a week, but, according to Raphaël Gaillard, president of the Union of Interns of the Hospitals of Paris, the average number of hours is 70. He said doctors are not even discussing the directive with the government as they consider it "so totally abstract that it seems inapplicable."

Italy: The standard working week for doctors in public and private hospitals is 40 hours, but the collective national contracts can shorten it (currently it is 34 hours of clinical activity plus four hours for continuing medical education) and can define the maximum working time, currently at 48 hours (as the weekly average over a four month period).

Doctors' hours will be central in the renewal of the contract for doctors in training because, according to the unions, many doctors work more than 58 hours a week when they are on-call.

Ireland: The directive is mired in an industrial relations limbo in Ireland. Despite ongoing discussions between the Irish Medical Organisation and the Health Service Employers Agency, no agreement exists on what constitutes junior doctors basic working hours. As a result, new rosters to comply with the 58 hour week cannot be introduced.

However it is estimated that one in five doctors are compliant with the directive because they have traditionally worked agreed shifts. The Irish Medical Organisation is concerned at a Department of Health interpretation of the directive that would allow doctors to be rostered for up to 91 hours a week and 11.5 days in succession.

Netherlands: Junior hospital doctors in the Netherlands have worked a basic 48 hour week since 1993, savs Alex van Bolderen, managing director of the Organisation of Salaried Doctors. But this does not include all hospital on-call hours.

The Dutch fear that last year's European Court ruling (BMJ 2003;327:640), in which al hospital on-call hours count towards the 48 hour working week, could cost $€ 400 \mathrm{~m}$ in extra health staff. They propose redefining on-call hours, allowing an extra seven of these on top of the 48 hours.

- According to the BMA's Brussels spokesman, Kevin Doran, the European Commission is due to issue further guidance during August that will clarify the rules about individual doctors opting out of the agreement and help clear up the question of whether being oncall, but not on hospital premises or actually working, counts as part of the working week.

Susan Mayor London, Jane Burgermeister Vienna, Katka Kosner Prague, Tiago Villanueva Lisbon, Annette Tuffs Heidelberg, Brad Spurgeon Paris, Fabio Turone Rome, Muiris Houston Dublin, Tony Sheldon Utrecht 